institute organisational changes-but whether he will learn from the outcry against him is something that most Western countries are unwilling to wait to find out. Intensive lobbying has been going on since January to persuade Japan to withdraw Dr Nakajima's candidacy. Failing that, Western diplomats hope to canvass support for a move against him at the meeting of the World Health Assembly in Geneva next week. A majority vote against Nakajima would effectively veto his reelection by turning it into a so called "important issue"-one that needs a two thirds majority at the executive board rather than Nakajima's simple 18 to 13 majority in January. Nakajima's opponents are confident that they could carry a third of the votes at the executive board, but they are not so sure of reaching the necessary majority in the World Health Assembly.

Behind the West's lobbying against Nakajima are solid threats. None of WHO's member states are threatening to resign as the United States and Britain did from Unesco over disagreements with its leadership in the 1980s. But they could reduce their voluntary contributions to WHO's international programmes. At present these almost equal the organisation's regular biennial budget of $\$ 750 \mathrm{~m}$ and include major programmes on AIDS, immunisation, diarrhoea, and human reproduction.

Diplomats from the United States, WHO's major donor, as well as from Denmark and Britain have made clear that their governments would consider withdrawing funds from these programmes if Dr Nakajima continues as director general. The other Scandinavian countries would be likely to follow
Denmark's lead. This would not mean an overall reduction in aid to the developing world as donors would transfer funds to other agencies such as the World Bank or to bilateral aid projects. But it would seriously damage coordinated international efforts. As most commentators acknowledge that the voluntary funded programmes are the most effective part of WHO, withdrawing funds would be a serious step.

Whatever happens in Geneva next week the damage to WHO is unlikely to be quickly reversed. If Nakajima remains WHO will be hampered by a director general who lacks the support of its major donors. If he is forced out by the assembly recriminations will continue long into the future, diminishing WHO's effectiveness. And even if, against all the odds, the Japanese government withdraws Dr Nakajima's nomination - the most damage limiting alternative-what of his replacement? Dr Mohammed Abdelmoumene, ex-deputy director general and Nakajima's main opponent in January, had the support of the West, but few were convinced that he was the best person for the job.

Selecting candidates by internal promotion has shown itself to be flawed. The leadership net should be thrown beyond the confines of WHO to bring in new organisational talent free from political influence. The world needs a WHO that works, which means effective and disinterested leadership.

FIONA GODLEE Assistant editor, $B M F$

1 Godlee F. Tuberculosis_“a global emergency.” BMY 1993;306:1147

\title{
Universal named testing of pregnant women for HIV
}

\section{Many benefits}

The British government's decision to support the universal named HIV testing of pregnant women where appropriate is welcome. ${ }^{1}$ Current evidence points to the benefit of initiating treatment before the patient's immune system is damaged irreversibly ${ }^{234}$; this will become more apparent with better antiviral treatment and prophylaxis. Furthermore, knowledge of their serological state allows patients to take measures to prevent them transmitting the infection sexually. During the antenatal period such knowledge enables a woman to make an informed decision about continuing with her pregnancy and, if she decides against termination, to take precautions to reduce the risk of transmitting infection to her child by avoiding breast feeding. ${ }^{5}$ Immediately after birth the infant can be monitored for HIV and, if infected, can benefit from the early treatment of HIV related diseases.

Against the benefits of testing have to be weighed its disadvantages, including cost, and obstetric units may have difficulty deciding whether to adopt universal testing. Accordingly, the scrutiny of available information about the extent of HIV infection among pregnant women in their area is vital so that an informed decision can be made. Britain's extensive programme of unlinked anonymous HIV testing of neonatal metabolic screening cards and residual serum from blood samples taken routinely from women during pregnancy permits monitoring of the prevalence of HIV among the country's pregnant women. ${ }^{67} \mathrm{By}$ comparing the number of infections detected by this approach with the number of women who, at the time of their pregnancy, were known to have tested HIV positive the level of clinical ascertainment of infection can be determined. As well as knowing the size of the group with HIV infection undetected it is important to realise its proportions of high risk and low risk patients; if undetected cases are principally women with features suggesting high risk who have previously been offered and declined testing then implementing universal testing might have little extra impact. Consequently, unlinked anonymous studies, particularly among pregnant populations, should collect limited information on risk categories. ${ }^{8}$

Our current knowledge of HIV infection in Britain suggests that most obstetric centres would be justified in continuing with a policy of selective testing of high risk patients. Although it has been argued that targeting discriminates against vulnerable groups of women, ${ }^{9}$ we believe that such practice is pragmatic, especially in view of the health service's financial constraints. Even so, where selective testing is performed the trend should be towards informing all women about the risks of HIV infection and the availability of HIV testing. All women, regardless of their risk, should be able to obtain such a test easily.

Some centres would benefit from a policy of universal testing. In parts of London and Scotland, where heterosexual transmission may be becoming the principal main means of spread, selective testing will miss increasing numbers of cases. In inner London, for example, only about one in five pregnant women infected with HIV are known to be so by their obstetricians. ${ }^{10}$

Counselling raises several difficult issues. We believe that pre-test counselling should be incorporated into the antenatal programme without the need for a special HIV counsellor. This will be conditional, however, on obstetricians and midwives receiving proper training. As Holman et al have indicated, counselling entails not only HIV testing but also 
providing information on how to reduce the risks of acquiring and transmitting the virus. ${ }^{11}$ Pre-test counselling also aims at ensuring fully informed consent. Although detailed discussion before testing is appropriate when a woman is particularly at risk of infection, for most women at very low risk the situation is different. Antenatal care is already complicated enough by explanations of routine tests, specific prenatal diagnostic tests, health messages, procedures, and relevant symptoms to report that patients are in danger of being overloaded with information. When the probability of a woman being infected with HIV is very low it seems unreasonable to conduct mandatory intensive counselling. Instead, written material should be available and a brief discussion with the midwife or obstetrician should take place. Questions from the patient may lead to a longer discussion, but we believe that women who wish to be tested should be exposed to a fairly simple procedure which nevertheless ensures explicit consent. This opinion has support from ethical groups ${ }^{12}$ and others with experience of screening clinics. ${ }^{13}$ Perhaps greater emphasis than currently exists should be placed on HIV testing at pre-pregnancy, well woman, and family planning clinics. Likewise, the offer of an HIV test to women who have an abortion should be considered.

An obstetric centre's principal objective should be to serve the needs of its pregnant population. Even in centres that promote universal testing the value and success of such programmes should be evaluated not only by measuring the uptake of HIV testing but also by seeking the views of pregnant women and staff. It is important that the emphasis should be on access to testing so that women can exercise choice.

The Department of Health's guidelines should reduce the disjointed nature of current procedures.' They provide a useful framework for local decision making about testing policy and emphasise the need for better data collection, access to information, and interdisciplinary collaboration, thus enabling health authorities to make decisions which are truly informed.

D J GOLDBERG

Honorary senior lecturer in HIV/AIDS epidemiology Communicable Diseases (Scotland) Unit,

Ruchill Hospital,

Glasgow G20 9NB

F D JOHNSTONE

Senior lecturer in obstetrics and gynaecology

Department of Obstetrics and Gynaecology,

University of Edinburgh,

Edinburgh EH3 9EW

1 Department of Health. Guidelines for offering voluntary named HIV antibody testing to women receiving antenatal care. London: $\mathrm{DoH}, 1992$. (PUCO(92)5.)

2 Moore RD, Hidalgo J, Sugland BW, Chaisson RE. Zidovudine and the natural history of the acquired immunodeficiency syndrome. N Engl I Med 1991;324:1412-6.

3 Graham NMH, Zeger SL, Park LP, Phair JP, Detels R, Vermund SH, et al. Effect of zidovudine and Pneumocystis carinii pneumonia prophylaxis on progression of HIV-1 infection to AIDS Lancet 1991;338:265-9.

4 Leoung GS, Feigal DW, Montgomery AB, Corhery K, Wardlaw L, Adams M, et al. Aerosolised pentamidine for prophylaxis against Pneumocystis carinii pneumonia. N Engl f Med 1990;323 769-75.

5 Dunn DT, Newell ML, Ades AE, Peckham CS. Risk of human immunodeficiency virus type 1 transmission through breast feeding. Lancet 1992;340:585-8.

6 Peckham CS, Tedder RS, Briggs M, Ades AE, Hjelm M, Wilcox AH et al. Prevalence of maternal HIV infection based on unlinked anonymous testing of newborn babies. Lancet 1990;335:516-9.

7 Gill ON, Adler MW, Day NE. Monitoring the prevalence of HIV. BMF 1989;229:1295-8.

8 Goldberg D, Mackinnon H, Smith R, Patel NB, Scrimgeour JB, Inglis JM, et al. Prevalence of human immunodeficiency virus among childbearing women and those undergoing termination human immunodeficiency virus among

9 Working Group on HIV Testing of Pregnant Women and Newborns. HIV infection, pregnant women and newborns. $\mathscr{F} A M A 1990 ; 264: 2416-20$.

10 Ades AE, Parker S, Berry T, Holland FJ, Davison CF, Cusi HD, et al. Prevalence of maternal HIV-1 infection in Thames regions, results from anonymous unlinked neonatal testing. Lancer 1991;337:1562-5.

11 Holman S, Sutherland A, Berthaud M, Cancellier F, Moroso S. Prenatal HIV counselling and testing. Clin Obstet Gynaecol 1989;32:445-55.

12 Boyd KM. HIV infection: the ethics of anonymised testing and of testing pregnant women. Ethics 1990;16:173-8.

13 McCarthy KH, Johnson MA, Studd JWW. Antenatal HIV testing. Br f Obstet Gynaecol 1992;99:867-8.

\title{
Where are the women in studies of coronary heart disease?
}

\author{
White middle aged men are not necessarily representative of all humankind
}

Coronary heart disease has traditionally been regarded as a disease of men, but it is also the leading cause of death and an important cause of morbidity and disability in women. Each year in Britain about 100000 men and 80000 women die of the disease.

Most research into the causes, prevention, diagnosis, and treatment of coronary heart disease has been conducted in men-more specifically, white middle aged men. Reasons for this include the well recognised excess of coronary heart disease among men and the easier accessibility of male populations to study. Although these studies have provided much insight into coronary heart disease, the dearth of data in women has caused concern. ${ }^{12}$

Medical practice relies on applying general principles to individual patients. Generalising findings from men to women may, however, not always be appropriate as the effects of some interventions may differ either qualitatively or quantitatively between men and women. These interventions include coronary artery bypass grafting, dietary manipulation or lipid lowering drugs for hypercholesterolaemia, and oestrogen replacement treatment.

Concentrating research on white middle aged men may have ramifications beyond the simple lack of data on the effects of interventions in women and other age or ethnic groups. With the increasing constraints on health services and the emphasis on using only diagnostic procedures and interventions that have been fully evaluated, there may be increasing pressures to exclude population groups who have not been studied from access to particular interventions because of lack of proved benefit. More subtly, research may reinforce the idea that coronary heart disease is a mainly male concern and may result in the relative neglect of the condition in women.

Several American studies have shown a gender bias in the management of coronary heart disease. Women with symptoms are less likely than men to be referred for investigations and treatment or are diagnosed and treated later in the course of their illness. ${ }^{34}$ Later diagnosis, referral, and treatment may result in a worse prognosis, including higher mortality and slower recovery. ${ }^{5}$ Some of these differences may be due to the way that health care is paid for in the United States-insurance plans may disadvantage nonworking women.

Although the NHS is meant to treat patients according to need, a paper in this week's journal by Petticrew and colleagues suggests that the management of coronary artery disease differs by gender in Britain (p 1164).${ }^{6}$ Having looked at hospital discharge data from North West and South West 